\title{
Exogenous lipoid pneumonia due to chronic occult aspiration in a patient with oesophageal colonic interposition
}

\author{
Mélissa Clément, ${ }^{1}$ Amira Benattia, ${ }^{1}$ Véronique Meignin, ${ }^{2}$ Abdellatif Tazi ${ }^{1,3}$
}

\begin{abstract}
${ }^{1}$ Pulmonology Department, Hôpital Saint-Louis, Assistance Publique - Hopitaux de Paris, Paris, île-de-France, France ${ }^{2}$ Pathology Department, Hôpital Saint-Louis, Assistance Publique - Hopitaux de Paris, Paris, Île-deFrance, France

${ }^{3}$ INSERM U976, Institut de Recherche Saint-Louis, Universite de Paris, Paris, Île-deFrance, France
\end{abstract}

\section{Correspondence to Dr Abdellatif Tazi;} abdellatif.tazi@aphp.fr

Accepted 29 May 2021

\section{DESCRIPTION}

A 51-year-old woman was seen at the emergency department for acute obstructive pyelonephritis diagnosed on an abdominal CT scan that was effectively managed by antibiotics and endoscopic double-J stent. Bilateral ground glass opacities were incidentally observed on the lower parts of the lungs. The patient had recent dyspnoea with normal peripheral oxygen saturation while breathing room air. Lung auscultation revealed bilateral lung crackles. Chest high-resolution CT (HRCT) showed a bilateral 'crazy-paving pattern' that, in the context of pandemic was initially considered suggestive of COVID-19 pneumonia, but a nasopharyngeal swab was negative for SARS-CoV-2 by RT-PCR. Strikingly, an air-containing cavity in the anterior mediastinum was also present (figure 1). History revealed that the patient had a prior oesophageal replacement by retrosternal colonic interposition following caustic ingestion 16 years before. A bronchoscopy with bronchoalveolar lavage (BAL) recovered a cream-coloured liquid with a lipid supernatant (figure 2A). BAL cell analysis displayed large optically empty vacuoles within most macrophages (figure 2B), as well as mild (20\%) lymphocytic alveolitis. Periodic acid-Schiff staining was negative. Oil red $\mathrm{O}$ staining confirmed macrophage lipid accumulation (figure 2C). SARS-CoV-2 RT-PCR in BAL was negative. Bronchial aspiration microscopy revealed acid-fast bacilli identified as Mycobacterium kansasii after culture, considered as colonisation according to the last ATS/ERS/ ESCMID/IDSA guidelines. ${ }^{1}$ The 1 -year follow-up

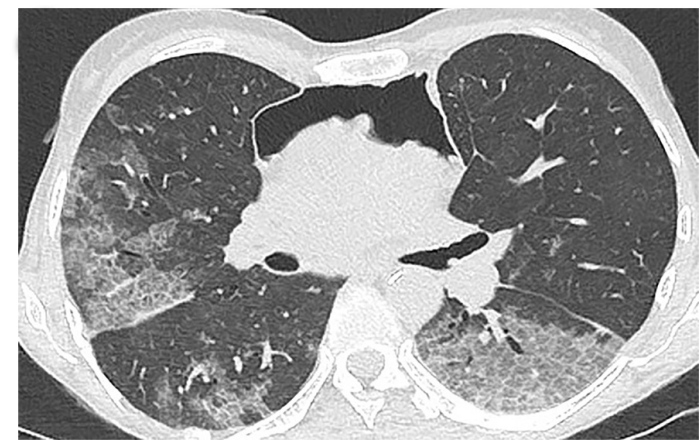

Figure 1 High-resolution CT of the chest showing bilateral ground glass opacities with a 'crazy-paving' pattern in the lower lobes. Note the presence of an air-containing cavity in the anterior mediastinum corresponding to oesophageal replacement by retrosternal colonic interposition.

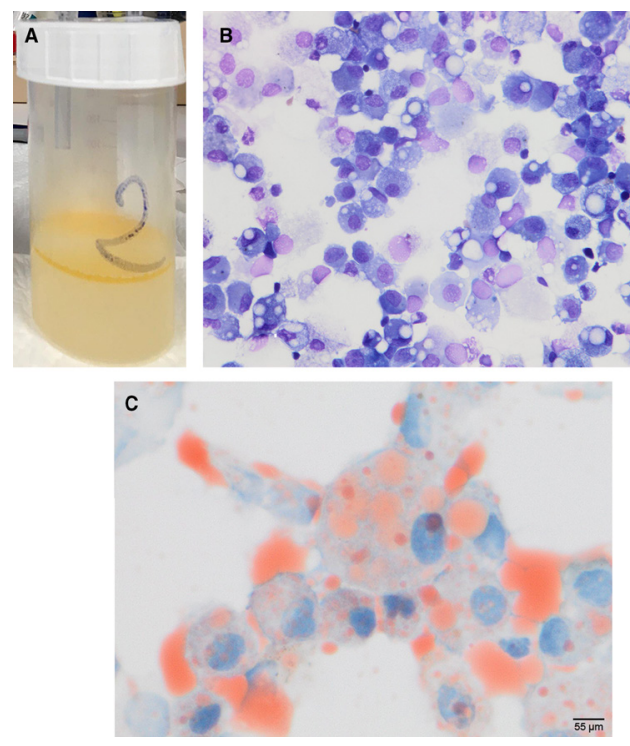

Figure 2 (A) Cream-coloured liquid with a lipid supernatant recovered by bronchoalveolar lavage. (B) Light microscopy showing alveolar macrophages containing optically empty vacuoles. May-GrunwaldGiemsa staining. original magnification $x 400$. (C) High-power field $(\times 1200)$ of oil red 0 colouration demonstrating the lipid content within macrophages.

showed clinical and radiological improvement without any sign of mycobacterial infection.

Resumption of the patient's interrogation revealed that she consumed dried yoghurt mixed with olive and sunflower oils daily for more than 10 years and had chronic regurgitations responsible for her lipoid pneumonia.

A crazy-paving pattern is a common although non-specific radiological finding characterised by scattered or diffuse ground glass attenuation with superimposed interlobular septal thickening and intralobular lines. ${ }^{2}$ A large spectrum of lung diseases may exhibit a crazy-paving pattern on HRCT, including infections, classically Pneumocystis jirovecii pneumonia, tumours (lung adenocarcinoma), pulmonary alveolar proteinosis and pulmonary haemorrhage. ${ }^{2}$ More recently, a crazypaving pattern has also been reported in a subset of patients with COVID-19 pneumonia. ${ }^{3}$ Although the distribution of the lung crazy-paving pattern and the presence of additional radiological findings are helpful for discriminating among potential differential diagnoses, lung HRCT alone is not sufficient for a definitive diagnosis. 
Exogenous lipoid pneumonia (ELP) is a rare but classical aetiology of lung ground glass opacities that may sometimes appear as a crazy-paving pattern. It is caused by the inhalation or aspiration of mineral, animal or vegetable oil. ${ }^{4}$ Factors predisposing to aspiration are often identified. Gastrointestinal diseases or surgery that increase the risk of aspiration or regurgitation of gastric contents and neurological diseases are the most common conditions associated with the risk of ELP. ${ }^{56}$ The most common cause of ELP is liquid paraffin used as a laxative and more rarely by fire-eater and oil-based nasal drops. ${ }^{56}$ Recently, ELP has also been reported in several cases of vaping-associated lung injury. ${ }^{7}$ The exposure to lipid substances may not be obvious at first sight, and repeated history interviews are sometimes required to identify the causative agent. Occasionally, ELP may be complicated by superimposed non-tuberculous mycobacterial colonisation or infection. ${ }^{8}$

\section{Learning points}

- Exogenous lipoid pneumonia is a rare but a classical aetiology of crazy-paving pattern on chest CT scan.

- A condition favouring oil aspiration or inhalation is present in most cases of exogenous lipoid pneumonia.

- Accurate and repeated clinical interview is essential to identify the causative lipid substance.

Acknowledgements The authors thank Dr Yaël Amar (Assistance PubliqueHôpitaux de Paris; Service dePneumologie, Hôpital Saint-Louis, Paris, France) for performing the procedure described and providing the bronchoalveolar lavage macroscopic image.

Contributors $M C, A B$ and AT wrote the manuscript. VM reviewed cytological findings and provided the corresponding figures. $A B$ and $A T$ reviewed all chest $C T$ scans and provided the imaging figures. All authors reviewed and approved the final version of the manuscript.

Funding The authors have not declared a specific grant for this research from any funding agency in the public, commercial or not-for-profit sectors.

Competing interests None declared.

Patient consent for publication Obtained.

Provenance and peer review Not commissioned; externally peer reviewed.

\section{REFERENCES}

1 Daley CL, laccarino JM, Lange C, et al. Treatment of nontuberculous mycobacterial pulmonary disease: an official ATS/ERS/ESCMID/IDSA clinical practice guideline. Eur Respir J 2020;56:2000535.

2 Rossi SE, Erasmus JJ, Volpacchio M, et al. "Crazy-paving" pattern at thin-section CT of the lungs: radiologic-pathologic overview. Radiographics 2003;23:1509-19.

3 Ye Z, Zhang Y, Wang Y, et al. Chest CT manifestations of new coronavirus disease 2019 (COVID-19): a pictorial review. Eur Radiol 2020;30:4381-9.

4 Betancourt SL, Martinez-Jimenez S, Rossi SE, et al. Lipoid pneumonia: spectrum of clinical and radiologic manifestations. AJR Am J Roentgenol 2010;194:103-9.

5 Gondouin A, Manzoni P, Ranfaing E, et al. Exogenous lipid pneumonia: a retrospective multicentre study of 44 cases in France. Eur Respir J 1996;9:1463-9.

6 Samhouri BF, Tandon YK, Hartman TE, et al. Presenting clinicoradiologic features, causes, and clinical course of exogenous lipoid pneumonia in adults. Chest 2021 doi:10.1016/j.chest.2021.02.037. [Epub ahead of print: 26 Feb 2021].

7 O'Carroll 0, Sharma K, Fabre A, et al. Vaping-associated lung injury. Thorax 2020;75:706-7.

8 Jouannic I, Desrues B, Léna $\mathrm{H}$, et al. Exogenous lipoid pneumonia complicated by Mycobacterium fortuitum and Aspergillus fumigatus infections. Eur Respir $J$ 1996;9:172-4.

Copyright 2021 BMJ Publishing Group. All rights reserved. For permission to reuse any of this content visit

https://www.bmj.com/company/products-services/rights-and-licensing/permissions/

BMJ Case Report Fellows may re-use this article for personal use and teaching without any further permission.

Become a Fellow of BMJ Case Reports today and you can:

- Submit as many cases as you like

- Enjoy fast sympathetic peer review and rapid publication of accepted articles

- Access all the published articles

Re-use any of the published material for personal use and teaching without further permission

Customer Service

If you have any further queries about your subscription, please contact our customer services team on +44 (0) 2071111105 or via email at support@bmj.com.

Visit casereports.bmj.com for more articles like this and to become a Fellow 